\title{
A Prospective Study on Impact of Anemia and Iron Supplementation in Pregnancy, Baptist Hospital, Bangalore, India
}

\author{
ZAHRA KHOSHDEL;, SHIBI TOMAS \\ Doctors of Pharmacy, Department of pharmacy practice, Karnataka College of Pharmacy, Bengaluru, India \\ Correspondence to Dr. Xshts zkhodhfrl, Email: niloofar.khoshdel99@yahoo.com
}

\begin{abstract}
Aim: A prospective study on Impact of Anemia and Iron Supplementation in Pregnancy, Baptist Hospital, Bangalore, India

Methodology: the prospective observational study was conducted for 6 months from September 2016_Febrry to 2017. All inpatients women who are pregnant and anemic. The patient data collection was used to collect all the details like inpatient number, age, sex, social history, history, laboratory data, diagnosis, therapeutic management. All inpatients diagnosed anemia in pregnancy and pregnant women without anemia. Fulfilling the inclusion criteria will be enrolled into the study and their prescriptions will be analyzed on daily basis. The prescription guidelines, Micromedex, interaction checker, drug interaction database, and Stockley's drug interaction book 8 edition. The drug interaction in prescription was collected and then compare with guidelines. When the analysis of prescription was completed then all data entered into the appropriate software and the results were gained.

Results: The present study was focused to find out the presence of anemia in 110 pregnant women who were admitted to gynecology and OBG wards of $\mathrm{BBH}$ (Bangalore Baptist Hospital). Presence study showed that anemia was Confirmed in 50 patients. Of these 28(25.4\%) of them diagnosed as mild anemic, $20(18.1 \%)$ Of them with Moderate and $2(1.8 \%)$ of them as severe anemic patients. The result of this study showed that LBW is higher in anemic women $19(25 \%)$ compared to non-anemic $17(21 \%)$.

Conclusion: The present study showed from a total of 110 patients were included in this study, anemia was confirmed in 50 patients. Of these $28(25.4 \%)$ of them diagnosed as mild anemic, $20(18.1 \%)$ Of them with Moderate and $2(1.8 \%)$ of them as severe anemic patients. More low-birth-weight (LBW) babies were born to anemic mothers. Anemia in pregnancy may be reduced by proper Iron and folic acid supplementation which can be improved through providing proper ANC services. Has also a recognizable association with fetal outcome.

Keywords: Anemia, Iron, anemia, iron supplementation, pregnancy, low birth weight.
\end{abstract}

\section{INTRODUCTION}

The arrangement of iron supplements to pregnant women is quite possibly the most broadly rehearsed general wellbeing measures, yet shockingly little is thought about the advantages of supplemental iron for the mother or her posterity during fetal or postnatal life. The reason for this article is to inspect distributed data on the impacts of frailty and iron deficiency on pregnancy outcome and to recognize current holes in the information ${ }^{1}$.

Around 2 billion individuals, adding up to more than $30 \%$ of the total populace are anemic, mostly because of iron deficiency ${ }^{1}$. Iron deficiency is the most pervasive and the most dismissed supplement deficiency on the planet, especially among pregnant women and kids, particularly in non-industrial nations ${ }^{2}$. It is additionally essentially common in industrialized nations. Assessments state that all around the world, 56 million pregnant women $(41.8 \%$ of the aggregate) are influenced with weakness, again generally because of iron deficiency ${ }^{3}$. In agricultural nations, this extent can be as high as $80 \%$ can imagine in South Asia $^{4}$, making pregnant moms defenseless to the expanded danger of mortality and diminished work limit. It might likewise prompt other perinatal intricacies like toxemia, low birth weight, prematurity, and perinatal mortality ${ }^{5}$. It is the least fortunate, generally helpless, and least taught who are excessively influenced by iron deficiency, and it is this gathering that stands to acquire the most by its decrease. Frailty, as characterized by low hemoglobin or hematocrit, is usually used to evaluate the seriousness of iron deficiency in populaces without high paces of jungle fever. The high physiological prerequisite for iron in pregnancy is hard to meet with most weight control plans. Thusly, pregnant women ought to regularly get iron supplementation, particularly in non-industrial nations. Prenatal iron supplementation isn't mandatory in many industrialized nations and the suggested portion is normally little (30mg ferrous iron every day) ${ }^{6}$. In any case, for agricultural nations, the proposal is an everyday portion of $60 \mathrm{mg}$ of iron for pregnant, non-anemic women for a half year and an expanded portion of $120 \mathrm{mg}$ of the iron day by day if the length of supplementation is more limited, if iron deficiency prevalence in women of a given nation is high, and if pregnant women are anemic. This supplement ought to incorporate $400 \mu \mathrm{g}$ of folic corrosive or lower portions if this sum isn't accessible ${ }^{7}$.

In India, pallor contributes straightforwardly to $20 \%$ of maternal demise and by implication to an additional $20 \%{ }^{2,3}$. The primary driver of Anemia in the agricultural nations in Antenatal women incorporates low dietary admission of iron and folic corrosive, helpless bioavailability of iron and fiber-rich Indian eating regimen, poor Retention of iron because of snare worm's pervasion and blood misfortune during conveyance and weighty feminine blood loss.4-6 Iron deficiency and Anemia during the antenatal period are related to low birth weight children, untimely birth, and increment perinatal and neonatal mortality. Anemia increases the risk of maternal morbidity \& mortality and adverse maternal outcome such as antepartum hemorrhage, post-partum hemorrhage \& puerperal sepsis ${ }^{8}$. 
Iron deficiency is responsible for about 95\% anemia during pregnancy, reflecting the increased demand for iron. During the first half of pregnancy, the iron requirement may not increase significantly and iron intake of $10-15 \mathrm{mg} /$ day from food is sufficient to cover the basal loss of $1 \mathrm{mg} /$ day. However, in the second half of pregnancy, iron requirements increase owing to an expansion of red blood cell mass and rapid growth of the fetus. Increased number of red blood

Cells and a higher hemoglobin mass require about $500 \mathrm{mg}$ iron. The iron requirement of the fetus on average is $300 \mathrm{mg}$. Thus, the total amount of iron necessary throughout a normal pregnancy is approximately $800 \mathrm{mg}$. This cannot be supplied in the diet, and iron supplementation is a must. [9] Women experience an assortment of physiological changes during pregnancy. Changes in the blood circulatory framework are especially striking, allowing typical fetal development. Indeed, even in typical pregnant women, the hemoglobin fixation diminishes with weakening as indicated by the increment in the volume of flowing blood. Since iron and folic corrosive in sums important to the embryo are specially shipped to the baby, the mother is probably going to create iron deficiency sickliness and folic corrosive deficiency weakness. About $20 \%$ of pregnant women endure paleness, and the greater part of the cases are iron deficiency, folic corrosive deficiency, or both ${ }^{10}$.

\section{MATERIALS AND METHODS}

the prospective observational study was conducted for 6 months from September 2016-February 2017. All inpatients women who are pregnant and anemic. Approval from the Institutional Ethics Committee and permission from the hospital was obtained before starting the study. The first step after the selection of the topic in the study was to design a data collection form. the patient data collection was used to collect all the details like inpatient number, age, sex, social history, history, laboratory data, diagnosis, therapeutic management. All inpatients diagnosed anemia in pregnancy and pregnant women without anemia. Fulfilling the inclusion criteria will be enrolled into the study and their prescriptions will be analyzed daily the prescription guidelines, Micromedex, Interaction Checker, Drug Interaction Database, and Stockley's Drug Interaction Book 8 Edition. The drug interaction in prescription was collected and then compare with guidelines. When the analysis of prescription was completed then all data entered into the appropriate software and the results were gained.

\section{RESULTS AND DISCUSSION}

Anemia is quite possibly the most regularly experienced clinical issues during pregnancy. In non-industrial nations, it is a reason for genuine worry as, other than numerous other unfavorable consequences for the mother and the embryo it contributes fundamentally high maternal mortality ${ }^{11}$. According to World Health Organization gauges, up to $56 \%$ of all women living in agricultural nations are anemic, hemoglobin level below $11 \mathrm{gm} / \mathrm{dl}$ in pregnant women constitutes anemia, and hemoglobin below $7 \mathrm{gm} / \mathrm{dl}$ is severe anemia
The present study was focused to find out the presence of anemia in 110 pregnant women who were admitted to gynecology and OBG wards of $\mathrm{BBH}$ (Bangalore Baptist Hospital) .to know about any correlation between adverse effects on the mother or fetus and serum hemoglobin/iron deficiency. We selected randomly 110 cases during 6 months and analyzed various parameters of the case sheet-like as laboratory data, demographic information, drug interaction, medical history, medical outcomes, and several hospitalizations.

Through this study majority numbers of patients were listed in the $20-30$ years age group $65(59 \%)$. also, in this study has been found that the percentage of anemic patients was more in the $20-30$ years age group $30(27.2 \%)$ compared to the $<20$ years age and $>30$ yeras age group.

This study has been supported by H.K. Cheema et al who in their study number of patients were listed more in 20-30 years age group 170(56.6\%). male patients exceeded female, with $119(59.5 \%)$. Also, in their study anemic patients were listed more in the 20-30 years age group ${ }^{12}$. Also, in this study, we find out non-educated women were having the maximum prevalence of anemia $32(30.9 \%)$ as compared to educated. almost similar finding was observed by SWATI PAWAR et al, in their result showed the presence of anemia were more in noneducated patients $(62.7 \%)$.observation of the present study could be explained by the fact that less-educated women have lack of knowledge about nutritious food, inadequate use of health services, lack of awareness regarding anemia and its effect on pregnancy and its outcomes ${ }^{14}$ Presence study showed from a total of 110 patients were included in this study, anemia was Confirmed in 50 patients. Of these $28(25.4 \%)$ of them diagnosed as mild anemic, $20(18.1 \%)$ Of them with Moderate, and $2(1.8 \%)$ of them as severe anemic patients. This result was the same as the result that found with Dereje Lelissa et al, in their result also out of 125 patients, 70 of them were anemic and among these cases, $41(53.2 \%)$ of them diagnosed with mild anemia, and $36(46.7 \%)$ of them as moderate anemic ${ }^{11}$. Our result also compared with Mushoumi Biswar et al, the study showed that the number of moderate anemias 107(76.9\%) was more than mild anemia $21(15.1 \%)^{15}$ (Table 1)

Likewise, a mother who had $<3$ antenatal visits were significantly more anemic $19(17.3 \%)$ in this study. This may be due to a lack of proper ante-natal care during pregnancy. as regular check-ups during pregnancy can detect anemia during pregnancy and other associated diseases. This result was compared with Reno Bedi et al, in their study also pregnant women who have $<3$ ANS visits were more anemic than those who had $>3$ ANS visits $^{16}$.(Table 2).

The result of this study showed that LBW is higher in anemic women 19(25\%) compared to non-anemic $17(21 \%)$. Also, the majority number of the male newborn $66(59.9 \%)$ were listed more. This study has been supported by Wali Lone et al, who in their study the number of LBW was higher in anemic women compare to nonanemic, and the male newborn was listed more $42(24 \%)$ than female ${ }^{20}$ (Table 3).

Out of the drugs used after delivery, the most drugs used was PPI drugs, then antibiotics, analgesic, and supplements (Table 4). 
In this study, we were found that there is some drugdrug interaction between drugs with each other. We find out33 drug-drug interactions, from these 12 of them were major and 21 of them were moderate, also the number of interactions was more in anemic patients compare to nonanemic. interaction between Metronidazole and Ondansetron was the most major drug-drug interaction, which caused an increased risk of Q-T interval prolongation, so ECG monitoring is recommended. Table 5. This result was the same as the result founded by STOCKLEY'S drug interaction edited by Karen Baxter, in their study also the concomitant use of Metronidazole and Ondansetron may increase the risk of Q-T interval prolongation and arrhythmia so if coadministration is required, monitoring of ECG may be warranted ${ }^{18}$.

Table 1: Severity of anaemia according to mothers age. (normal range $>10.9 \mathrm{~g} / \mathrm{dl}$ )

\begin{tabular}{|c|c|c|c|c|c|c|}
\hline \multirow[t]{2}{*}{ Age } & \multicolumn{2}{|c|}{ Mild $(10-10.9 \mathrm{~g} / \mathrm{dl})$} & \multicolumn{2}{|c|}{ Moderat $(7-<10 \mathrm{~g} / \mathrm{dl})$} & \multicolumn{2}{|c|}{ Sever $(<7 g / d l)$} \\
\hline & $\mathbf{n}$ & \%age & $\mathbf{n}$ & \%age & $\mathbf{n}$ & \%age \\
\hline$<20$ YRS & 3 & $2.7 \%$ & 2 & $1.8 \%$ & 0 & $0 \%$ \\
\hline 20-30YRS & 15 & $13.6 \%$ & 13 & $11.8 \%$ & 2 & $1.8 \%$ \\
\hline$>30$ YRS & 10 & $9.09 \%$ & 5 & $4.5 \%$ & 0 & $0 \%$ \\
\hline Total & 28 & $25.4 \%$ & 20 & $18.1 \%$ & 2 & $1.8 \%$ \\
\hline
\end{tabular}

Table 2: Association of ANC Variable with anemia

\begin{tabular}{|c|c|c|c|c|c|c|c|}
\hline \multirow{2}{*}{\multicolumn{2}{|c|}{ ANC variable }} & \multicolumn{2}{|c|}{ Anaemic } & \multicolumn{2}{|c|}{ Nonanamic } & \multicolumn{2}{|c|}{ Total } \\
\hline & & & $\%$ & & $\%$ & & $\%$ \\
\hline \multirow[t]{3}{*}{ Age of mothers } & $<20$ YRS & 5 & $4.5 \%$ & 7 & $6.3 \%$ & 12 & $10.8 \%$ \\
\hline & 20-30YRS & 30 & $27.2 \%$ & 35 & $31.8 \%$ & 68 & $59 \%$ \\
\hline & $>30$ YRS & 15 & $13.6 \%$ & 18 & $16.3 \%$ & 33 & $29.9 \%$ \\
\hline \multirow[t]{2}{*}{ Anc visit } & $<3$ & 19 & $17.2 \%$ & 17 & $15.4 \%$ & 36 & $32.6 \%$ \\
\hline & $>3$ & 31 & $28.1 \%$ & 43 & $39.09 \%$ & 74 & $67.3 \%$ \\
\hline \multirow[t]{2}{*}{ Medical illness } & Deseased & 18 & $16.3 \%$ & 17 & $15.4 \%$ & 35 & $31.7 \%$ \\
\hline & Undiseased & 32 & $29.09 \%$ & 43 & $39.09 \%$ & 75 & $68.3 \%$ \\
\hline \multirow[t]{3}{*}{ Iron and folic acid supplementation } & Adequate & 18 & $16.3 \%$ & 30 & $27.2 \%$ & 48 & $43.5 \%$ \\
\hline & Inadequate & 15 & $13.6 \%$ & 21 & $19.09 \%$ & 36 & $32.6 \%$ \\
\hline & Not taken & 17 & $15.4 \%$ & 9 & $8.1 \%$ & 26 & $23.5 \%$ \\
\hline
\end{tabular}

Table 3: Association of fetal and newborn outcomes with anemia

\begin{tabular}{|c|c|c|c|c|c|c|c|}
\hline \multirow{2}{*}{\multicolumn{2}{|c|}{ Fetal outcome }} & \multicolumn{6}{|c|}{ Anaemia status } \\
\hline & & \multicolumn{2}{|c|}{ Anemic } & \multicolumn{2}{|c|}{ Non-anameic } & \multicolumn{2}{|c|}{ Total } \\
\hline \multirow{2}{*}{$\begin{array}{l}\text { W.t of } \\
\text { fetal }\end{array}$} & $>2.5$ & 31 & $17.1 \%$ & 43 & $35.7 \%$ & 74 & $52.9 \%$ \\
\hline & $<2.5$ & 19 & $25.7 \%$ & 17 & $21.4 \%$ & 36 & $47.1 \%$ \\
\hline \multirow[t]{2}{*}{ Gender } & Male & 29 & $26.3 \%$ & 37 & $33.6 \%$ & 66 & $59.9 \%$ \\
\hline & Female & 21 & $19.09 \%$ & 23 & $20.9 \%$ & 44 & $40.1 \%$ \\
\hline \multirow{2}{*}{$\begin{array}{l}\text { Grade } \\
\text { number }\end{array}$} & $<1$ & 27 & $24.5 \%$ & 23 & $20.9 \%$ & 50 & $45.4 \%$ \\
\hline & $>2$ & 23 & $20.9 \%$ & 37 & $33.6 \%$ & 60 & $54.6 \%$ \\
\hline
\end{tabular}

Table 4: Drugs used after delivery

\begin{tabular}{|c|c|c|c|}
\hline Drug class & Drug name & Number & Total \\
\hline \multirow[t]{5}{*}{ Anti biotics } & Piperacillin & 5 & \multirow[t]{5}{*}{69} \\
\hline & Metronidazole & 17 & \\
\hline & Augmentin & 5 & \\
\hline & Cephalexin & 23 & \\
\hline & Cefazoline & 19 & \\
\hline \multirow{2}{*}{ Ppi } & Ranitidine & 41 & \multirow[t]{2}{*}{74} \\
\hline & Pantoprazole & 33 & \\
\hline \multirow[t]{2}{*}{ Supplement } & Calcium & 25 & \multirow[t]{2}{*}{54} \\
\hline & Iron & 29 & \\
\hline \multirow[t]{2}{*}{ Analgesic } & Paracetamol & 21 & \multirow[t]{2}{*}{63} \\
\hline & Diclofenac & 42 & \\
\hline Antiemetic & Ondansetron & 24 & 24 \\
\hline Hormone/thyroid & Thyronorm & 17 & 17 \\
\hline Others & Nifedipine/levetriacetam & 19 & 19 \\
\hline
\end{tabular}

Table 5: Drug-drug interaction

\begin{tabular}{|l|l|l|l|l|}
\hline Drugs name & Severity & Effect & Anemic & Non-anemic \\
\hline Metronidazole/ Ondansetron & Major & Increased q-t interval prolongation, arrhythmia & 7 & 5 \\
\hline Thyronorm/Calcium & Moderate & Reduced calcium absorption & 8 & 4 \\
\hline Ondansetron /tramadol & Moderate & Deacresed tramadol efficacy & 3 & 6 \\
\hline
\end{tabular}




\section{CONCLUSION}

Through this study majority numbers of patients were listed in the 20-30 years age group $(n=65),(59 \%)$. also, in this study has been found that the percentage of anemic patients was more in the 20-30 years age group $(n=30)$, (27.2\%).

The present study showed from a total of 110 patients were included in this study, anemia was confirmed in 50 patients. Of these $28(25.4 \%)$ of them diagnosed as mild anemic, 20 $(18.1 \%)$ Of them with Moderate and $2(1.8 \%)$ of them as severe anemic patients.

In this study, we were found that there is some drugdrug interaction between drugs with each other. We find out33 drug-drug interactions, from these 12 of them were major and 21 of them were moderate, also the number of interactions was more in anemic patients compare to nonanemic.

Variables related to anemia in pregnancy were Caste, dietary - propensity, Education, Occupation, Sociomonetary status, ANC Visit, Iron and folic acid supplementation while Residence Religion Number of Children Type of family Inter-Pregnancy Interval (Months) were not associated. These should be improved by providing proper ANC services. More low-birth-weight (LBW) babies were born to anemic mothers. Anemia in pregnancy might be diminished by legitimate Iron and folic corrosive supplementation which can be improved through giving appropriate ANC administrations. Has a likewise conspicuous relationship with fetal outcome.

\section{REFERENCES}

1. World Health Organization. (1992). The prevalence of anemia in women: a tabulation of available information (No. WHO/MCH/MSM/92.2. Unpublished). World Health Organization.

2. Peña-Rosas, J. P., \& Viteri, F. E. (2009). Effects and safety of preventive oral iron or iron+ folic acid supplementation for women during pregnancy. Cochrane database of systematic reviews, (4).

3. De Benoist, B., Cogswell, M., Egli, I., \& McLean, E. (2008). Worldwide prevalence of anaemia 1993-2005; WHO Global Database of anaemia.

4. World Health Organization. The World Health ReportConquering Suffering, Enriching Humanity (1997). Geneva, Switzerland

5. Murphy, J. F., Newcombe, R. G., O'riordan, J., Coles, E. C., \& Pearson, J. F. (1986). Relation of haemoglobin levels in first and second trimesters to outcome of pregnancy. The Lancet, 327(8488), 992-995.

6. Bothwell, T. H. (2000). Iron requirements in pregnancy and strategies to meet them. The American journal of clinical nutrition, 72(1), 257S-264S.
7. Stoltzfus, R. J., Mullany, L., \& Black, R. E. (2004). Iron deficiency anaemia. Comparative quantification of health risks: global and regional burden of disease attributable to selected major risk factors, 1, 163-209.

8. Bardisi, S. M. (2015). Evaluation of anemia during pregnancy at Rusaifah primary health care center in Makkah Al Mukarramah, Saudi Arabia. International Journal of Medical Science and Public Health, 4(5), 694-700.

9. Bekele, A., Tilahun, M., \& Mekuria, A. (2016). Prevalence of anemia and Its associated factors among pregnant women attending antenatal care in health institutions of Arba Minch town, Gamo Gofa Zone, Ethiopia: A Cross-sectional study. Anemia, 2016.

10. Kumari, S., \& Priya, J. (2000). Prevalence of anemia risk factors in pregnant women. Nutrition, 72(1), 257S-S264.

11. Lelissa, D., Yilma, M., Shewalem, W., Abraha, A., Worku, M., Ambachew, H., \& Birhaneselassie, M. (2015). Prevalence of anemia among women receiving antenatal care at Boditii Health Center, Southern Ethiopia. Age, 15(19), 25.

12. Cheema, H. K., Bajwa, B. S., Kaur, K., \& Joshi, H. (2016). Prevalence and possible risk factors of anaemia in different trimesters of pregnancy. International Journal of Contemporary Medical Research, 3(4), 1194-1197.

13. Khan, M. S., Srivastav, A., \& Dixit, A. K. (2014). The burden of anaemia amongst antenatal women in the rural population of northern India. International Journal of Scientific Study, 1(4), 40-42.

14. Pawar, S. Demographic Profile, anemia status and fetal outcome of the pregnant women attending at tertiary care hospital, Bikaner.

15. Biswas, M., \& Baruah, R. (2014). Maternal anaemia associated with socio-demographic factors among pregnant women of Boko-Bongaon Block Kamrup, Assam. Indian Journal of Basic and Applied Medical Research, 3(2), 712721.

16. Bedi, R., Acharya, R., Gupta, R., Pawar, S., \& Sharma, R. (2015). Maternal factors of anemia in 3rd trimester of Pregnancy and its association with fetal outcome. International Multispecialty Journal of Health (IMJH), 1(7), 46-53.

17. Farah Wali Lone1, Rahat Najam Qureshi, Maternal anaemia and its impact on perinatal outcome, June 5, 2007

18. Baxter, K., \& Preston, C. L. (Eds.). (2010). Stockley's drug interactions (Vol. 495). London: Pharmaceutical Press.

19. Uche-Nwachi, E. O., Odekunle, A., Jacinto, S., Burnett, M., Clapperton, M., David, Y., ... \& Singh, R. (2010). Anaemia in pregnancy: associations with parity, abortions and child spacing in primary healthcare clinic attendees in Trinidad and Tobago. African health sciences, 10(1), 66.

20. Sharma, J. B., \& Shankar, M. (2008). Anaemia in pregnancy. Differential Diagnosis in Obstetrics and Gynaecology: An AZ, 31, 19.

21. Khalafallah, A. A., \& Dennis, A. E. (2012). Iron deficiency anaemia in pregnancy and postpartum: pathophysiology and effect of oral versus intravenous iron therapy. Journal of pregnancy, 2012. 